\title{
\#26
}

\section{EL NEOBARROCO Y \\ LA REVOLUCIÓN \\ DESPUÉS DE LA \\ REVOLUCIÓN}

\section{León Felipe Barrón Rosas}

Universidad Autónoma de Querétaro, México

https://orcid.org/0000-0001-5544-3114

Ilustración || @ Ana Rodríguez - Todos los derechos reservados

Texto || @ León Felipe Barrón Rosas - Licencia: Atribución-NoComercial-SinDerivadas 4.0 Internacional de Creative Commons

\section{(c) (1) @ (}




\section{$452^{\circ} \mathrm{F}$}

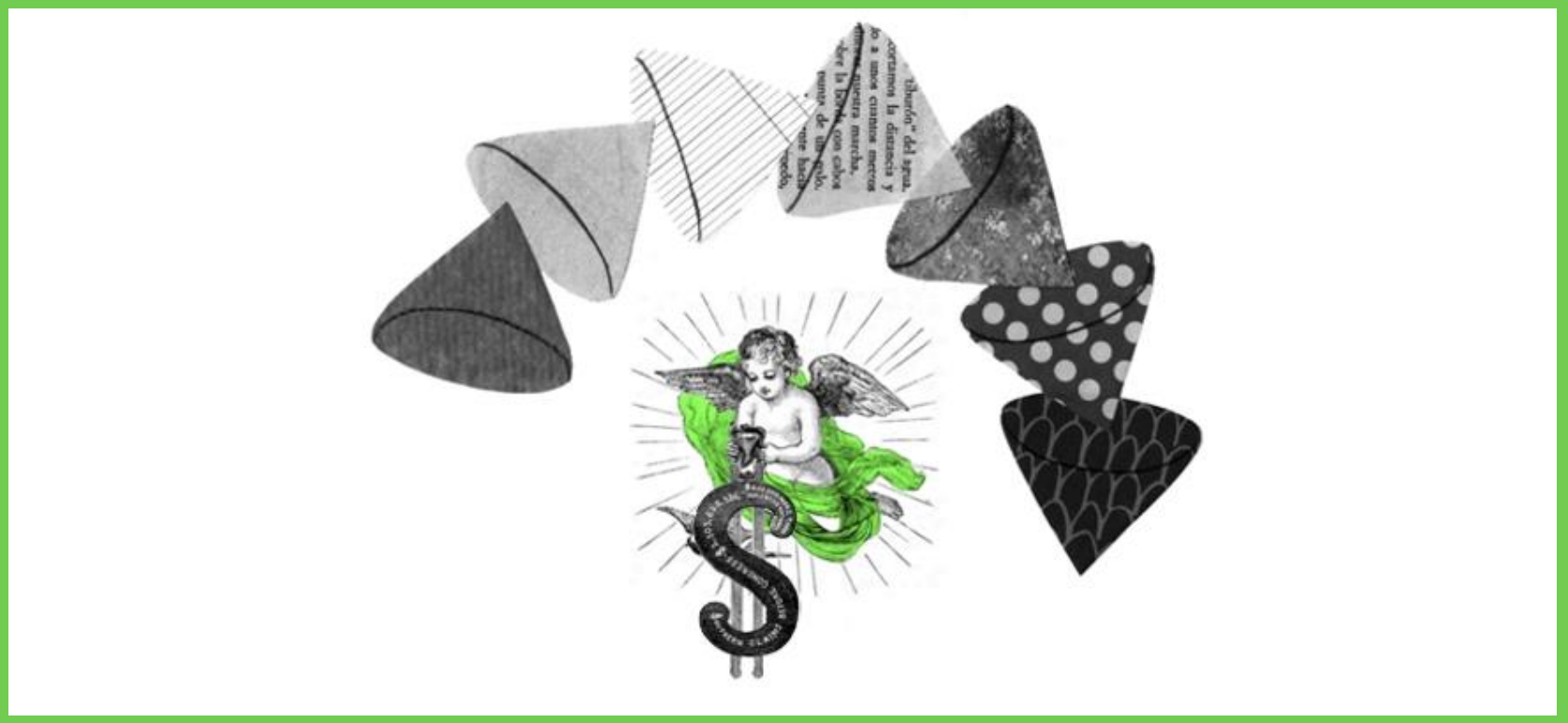

Resumen || El presente trabajo tiene como objetivo analizar el concepto de revolución presente en el neobarroco de Severo Sarduy. En la obra del escritor cubano existe una preocupación profunda por replantear la idea de revolución en un contexto en el cual intelectuales como Octavio Paz anunciaron la muerte de ésta. Frente a este escepticismo respecto a lo revolucionario, Sarduy no optó por abandonar la idea de revolución, sino que la reelaboró a través de la combinación de una persistente crítica al capitalismo y la crítica a la metafísica occidental presente en la filosofía francesa de su época. La unión de ambas críticas es lo que hace peculiar su concepto de revolución, en el que también el lenguaje y el cuerpo tienen un lugar central para plantear lo revolucionario.

Palabras clave || Neobarroco | Revolución | Crítica anticapitalista | Crítica a la metafísica occidental | Lenguaje | Cuerpo

Abstract || The aim of this paper is to analyze the concept of revolution that is present in the neobaroque of Severo Sarduy. There is, in the work of the Cuban writer, a deep concern for redefining the idea of revolution in a context in which intellectuals like Octavio Paz announced its death. Facing this skepticism regarding the revolutionary, Sarduy did not opt for abandoning the idea of revolution, but he reworked it through the combination of a persistent critique of capitalism and the critique of western metaphysics that was present in French philosophy of his time. The union of both critiques is what makes his concept of revolution peculiar, in which language and body have a central place to raise the revolutionary.

Keywords || Neobaroque | Revolution | Anti-capitalist critique | Western metaphysics critique | Language | Body

Resum || El present treball té com a objectiu analitzar el concepte de revolució present en el neobarroc de Severo Sarduy. En l'obra de l'escriptor cubà existeix una preocupació profunda per replantejar la idea de revolució en un context en el qual intel-lectuals com Octavio Paz van anunciar la mort d'aquesta. Davant d'aquest escepticisme respecte a allò revolucionari, Sarduy no va optar per abandonar la idea de revolució, sinó que la va reelaborar a través de la combinació d'una persistent crítica al capitalisme i la crítica a la metafísica occidental present en la filosofia francesa de la seva època. La unió d'ambdues crítiques és el que fa peculiar el seu concepte de revolució en el qual el llenguatge i el cos també tenen un lloc central per a platejar allò revolucionari.

Paraules clau || Neobarroc | Revolució | Crítica anticapitalista | Crítica a la metafísica occidental | Llenguatge | Cos 


\section{Introducción}

En la introducción de su libro La polis literaria (2018), Rafael Rojas menciona que la literatura latinoamericana después de la Revolución cubana estuvo enmarcada en el contexto de lucha contra las dictaduras por parte de los diversos grupos de izquierda inclinados hacia el socialismo y la democracia. Sin embargo, no podría asegurarse que en esta literatura estuviesen enteramente asimiladas las políticas emanadas desde la isla, puesto que «Cada uno de los escritores latinoamericanos desarrolló un concepto de Revolución» (2018: 12). Este es el caso de Severo Sarduy, quien en sus ensayos «El barroco y el neobarroco» (1972) y Barroco (1974), presentó su estética neobarroca ligada al concepto de revolución. Al final de ambos textos, Sarduy describió al barroco como «Barroco de la revolución». No obstante, la crítica centrada en la obra del escritor cubano generalmente toma este aspecto como algo tangencial y, por tanto, hace una lectura de los elementos organizadores de la estética neobarroca desligada del concepto de revolución. Esto ha tenido generalmente como consecuencia una lectura de la obra sarduyana desligada de su contexto de producción y de las polémicas intelectuales en Latinoamérica respecto a los movimientos sociales relacionados con lo revolucionario. El trabajo de Rafael Rojas es una excepción y, por tal motivo, se vuelve una referencia necesaria con la cual se discute.

Este trabajo ${ }^{1}$ tiene la mira puesta en leer el neobarroco de Sarduy considerando el concepto de revolución como aspecto central y motivador de la propuesta entera del neobarroco, con lo cual se llega a la conclusión de que la obra del escritor cubano debe ser comprendida a partir de este elemento que le da forma. Una lectura de este tipo implica situar, primeramente, al neobarroco en el espacio de discusión donde se produjo, para así considerarlo como una propuesta estético-ideológica interesada por las problemáticas políticas de su momento.

Que la crítica lea generalmente el neobarroco obliterando la revolución se debe probablemente a que Sarduy no dio una definición extensa de lo que entendía por ésta. En este sentido, el aporte de este trabajo consiste en realizar un rastreo de la configuración de este concepto a través de algunos de sus ensayos y entrevistas. De este modo se articularán los elementos que integran la noción de revolución; algunos de ellos provienen de una lectura muy particular del marxismo y de la integración a ella de conceptualizaciones provenientes del posestructuralismo, en particular de las obras de Jacques Derrida y de Michel Foucault. Es de remarcar que el marxismo es algo escasamente mencionado al abordar el neobarroco; por el contrario, la presencia posestructuralista ha sido largamente mencionada; sin embargo, se hace de un modo aislado y desvinculado de la voluntad subyacente en el neobarroco de replantear lo revolucionario. La lectura que hacemos aquí integra ambos espectros teóricos.

El camino trazado para el desarrollo de lo anterior tiene como punto de arranque una comparación entre dos posturas relacionadas con el concepto de revolución. Una es representada por Octavio Paz y la otra por el propio Sarduy. Aunque ambos tenían grandes afinidades estéticas e ideológicas, lo cual les permitió una relación de amistad estrecha, su lectura 
de lo revolucionario es diferente. Al final de su vida, el primero anunció la muerte de la revolución, mientras que el segundo no desistió de ella; sin embargo, es necesario señalar que ambas apreciaciones sobre la revolución parten de una crítica a los resultados de los movimientos históricos revolucionarios; sin embargo, a pesar de partir de una crítica a la revolución, su conclusión es diferente. Al contrastar el abandono paziano de la revolución con la persistencia y voluntad de reelaborarla conceptualmente en la dimensión estética, por parte de Sarduy, el neobarroco queda situado en el horizonte de las polémicas latinoamericanas sobre lo revolucionario. La justificación de elegir a Paz para analizar el concepto de revolución mediante una comparación radica principalmente en el peso que tuvo el mexicano en el espacio intelectual latinoamericano para interpretar los fenómenos sociales revolucionarios, y porque su postura final sobre la revolución contrasta fuertemente con el deseo de no abandonar la revolución y rescatarla mediante su reformulación. Este es el principal objetivo del primer apartado.

En el segundo apartado se profundiza en la relación existente en el neobarroco entre el marxismo y las teorías posestructuralistas. Aquí, se vuelve importante la obra de Bolívar Echeverría, pues fue quien logró capturar de gran manera los rasgos de afinidad que tiene el neobarroco como crítica a la modernidad capitalista y el marxismo. Si bien existen análisis sobre la lectura realizada por Echeverría al neobarroco, la diferencia con aquellos trabajos y éste radica en el análisis de textos del filósofo marxista que no refieren al neobarroco de Sarduy, pero que permiten ahondar más en su lectura particular del marxismo.

Por último, se analiza cómo el concepto de revolución del neobarroco integra la pretensión de una trasformación radical de lo social, que para Sarduy se estructura a partir de una escritura que da forma al «fundamento epistemológico» de la vida burguesa, y la revolución del sujeto, donde el cuerpo adquiere un rol fundamental. Así, quedan comprendidas dos transformaciones frecuentemente separadas: la de lo macro y la de lo micro.

El concepto de revolución en el neobarroco es insoslayable; por ello la importancia de interrogarse sobre la construcción y el significado de ella en la obra del escritor cubano para comprender su aporte en un contexto de desconfianza hacia lo que se anunciaba como revolucionario. Su posicionamiento respecto a la revolución cumplía con el objetivo de replantear la revolución después de la revolución, así como al sujeto revolucionario, pues pareciera que la tesis que subyace en el neobarroco respecto a esto es que no puede haber revolución sin una revolución del sujeto y del lenguaje.

\section{Severo Sarduy y Octavio Paz: la duda sobre la persistencia o el fin de la revolución}

En uno de los varios textos breves escritos por Severo Sarduy a manera de imágenes que podrían ser descritas como autobiográficas, y reunidos por Gustavo Guerrero en la compilación de su Obra Completa (1999a) bajo el 
título Autorretratos, el escritor cubano plasmó la afinidad que había entre él y Philippe Sollers, así como su «complicidad» y «fidelidad» hacia Octavio Paz. Con el escritor y teórico francés tenía varios intereses en común, uno de ellos fue la reflexión en torno al concepto de revolución y su relación con el lenguaje ${ }^{2}$; con el segundo compartía la atracción y el gusto por «el pensamiento asiático» (2002: 27).

Paz en Oriente (1990) es otro texto donde Sarduy evocó al autor de Corriente alterna; ahí recogió la interpretación paziana sobre la obra Novia desnuda por sus solteros de Marcel Duchamp. En el mismo texto, Sarduy destacó cómo el poeta mexicano dejó ver «el poder, hasta entonces solapado o invisible, de una ilusión» (2002: 28). La ilusión referida era aquella que designaba al castrismo como «un nuevo humanismo, una invención americana, una libertad o una democracia» (28). La lectura de Sarduy sobre el nobel mexicano reflejaba su postura ante la Revolución cubana, tema prácticamente ausente en sus publicaciones realizadas después de dejar la isla, excepto en este escrito donde surge bajo el pretexto de hablar de lo ilusorio de algunos hechos dados como verdades.

Su posicionamiento respecto al régimen cubano lo expresaba Severo Sarduy generalmente en lo privado (Rojas: 2013), tal como se ve en el ensayo "Plumas, sí: De donde son los cantantes y Cuba» de Roberto González Echevarría (2002). El crítico cubano y amigo de Sarduy incluyó en su texto fragmentos de la correspondencia sostenida entre ellos; en esas cartas manifestaba su posición sobre la política de la isla. Si en los momentos inmediatamente posteriores a la Revolución cubana, Sarduy expresó su entusiasmo por ella, especialmente en sus textos de crítica plástica ${ }^{3}$, escritos antes de salir de la isla y poco después, para inicios de la década de los noventa era evidente que ese ánimo se había esfumado enteramente. Su crítica al régimen socialista cubano la manifestó en unas escasas, pero contundentes líneas de Paz en Oriente, donde retrató a la Revolución cubana como una ilusión, como se lee en sus palabras citadas unas líneas arriba.

Para 1990, año de la entrega del Premio Nobel a Octavio Paz y fecha del escrito Paz en Oriente, la intelectualidad latinoamericana, que en los sesenta había apoyado la Revolución cubana, llevaba bastantes años desencantada de ella, especialmente por sucesos como el famoso «Caso Padilla». Para ese año, varios escritores cubanos se encontraban en el exilio debido a su postura confrontada con la política de la isla. Dentro de esa lista se hallaban el propio Severo Sarduy, Guillermo Cabrera Infante, Reinaldo Arenas, Lorenzo García Vega, entre otros. A este contexto latinoamericano se sumaba la reciente caída del Muro de Berlín y el panorama político internacional que constataba el fracaso de la Unión Soviética y el socialismo real.

Al escenario político e ideológico en el cual Severo Sarduy escribió sobre Octavio Paz, habría que añadir el desencanto y la desconfianza hacia el proyecto civilizatorio de la modernidad reflejados en las teorías posmodernas, y el triunfo de la globalización neoliberal, que para este momento había dejado de tener un antagonista que ejerciera resistencia a su despliegue global. Pese al contexto desolador producido por la caída de 
las ilusiones de la modernidad y la decepción producida por el socialismo rea/ ${ }^{4}$, Severo Sarduy se atrevió a utilizar un concepto fundamental de la modernidad para adjetivar el trabajo crítico del poeta mexicano: revolución. De acuerdo a él, Paz había realizado una lectura «revolucionaria» de la pintura de Marcel Duchamp. Aunque en primera instancia pareciera que no hay relación entre la idea de revolución dentro de lo estético y la revolución como producto de la lucha social, habría que subrayar que para el escritor cubano sí existía dicha relación. Desde sus textos de juventud hasta estos años, el concepto de revolución estuvo siempre presente en su producción estética. Es precisamente «la ubicuidad tópica de la revolución», que describió Reinhart Koselleck ${ }^{5}$ (1993: 67), la que le permitió a Severo Sarduy subrayar la dimensión revolucionaria del neobarroco y vincularla con la producción de saberes en otros ámbitos. En su obra quedan referidos varios tipos de revolución como la cosmológica, la estética, la del lenguaje, la de los cuerpos y, por supuesto, la revolución entendida a partir de la lucha de clases. Es por esto último que el escritor cubano pudo escribir:

[...] ser barroco hoy significa amenazar, juzgar, y parodiar la economía burguesa, basada en la administración tacaña de los bienes, en su centro y fundamento mismo: el espacio de los signos, el lenguaje, soporte simbólico de la sociedad (1999b: 1250).

En esta definición del ser barroco como ser contrapuesto al orden social estructurado por la vida burguesa centrada en la acumulación de capital, el neobarroco se presenta como una vía que amenaza desde los signos, pues si el orden del mundo se gesta a través de ellos, una revolución necesariamente debe estar dirigida a un reordenamiento de los mismos.

Pese a que la idea de revolución en el neobarroco tiene un peso enorme, generalmente es reducida a esta cita:

Barroco que en su acción bascular, en su caída, en su lenguaje pinturero, a veces estridente, abigarrado y caótico, metaforiza la impugnación de la entidad logocéntrica que hasta entonces lo y nos estructuraba desde su lejanía y autoridad; barroco que recusa toda instauración, que metaforiza al orden discutido, al dios juzgado, a la ley trasgredida. Barroco de la revolución (Sarduy, 1999b: 1404).

Con este fragmento concluye el ensayo El barroco y el neobarroco publicado en 1972 y se reitera, porque la escritura neobarroca es repetitiva, en las últimas líneas de Barroco de 1974. La idea de revolución barroca expuesta en estos trabajos contrasta notablemente con aquella que Rafael Rojas describe en La polis literaria para hablar de la obra del escritor cubano. En cierta medida, Severo Sarduy comparte la idea paziana de que las revoluciones se trasforman en dictaduras sangrientas que provocan el retorno de lo reprimido. Como señala Rafael Rojas: «Sarduy no niega que la revolución tenga un efecto liberador, pero piensa, psicoanalíticamente, que esa liberación desata atavismos reprimidos» (2018: 249). Sin embargo, cuando Sarduy apuntala al neobarroco como una estética revolucionaria, lo hace desde otras claves interpretativas de la idea de revolución. El neobarroco no sigue la misma concepción de ésta como acontecimiento desencadenador de actos de represión, censura y opresión. Sarduy criticaba a todo tipo de revolución que concluyera en «fobias, compulsiones, agresividades, ansiedad, toda una serie de infatuaciones o 
inseguridades, arrogancias o autocastigos que saltan sobre el sujeto" (en Rojas, 2018: 248), por consiguiente, ésta no podría ser la línea interpretativa de la revolución neobarroca.

La obra de Sarduy se sumó a las discusiones políticas e ideológicas del momento en Latinoamérica, y recuperó la noción de revolución en un momento en el que Octavio Paz consideraba que los movimientos revolucionarios acontecidos en el siglo XX habían llevado únicamente a la creación de regímenes autoritarios. La palabra revolución para Paz se había convertido en la «forma demagógica de nombrar distintos tipos de dictadura» (Rojas, 2018: 24).

Paz en Oriente quizá fue escrito por Sarduy a la par de la lectura de Poesía, mito, revolución del poeta mexicano, quien lo redactó a razón de la recepción del premio Alexis de Tocqueville en 1989 en Francia. En este discurso publicado en el número 152 de la revista Vuelta, el nobel mexicano describió la idea de revolución como elemento propio y esencial de la modernidad. La revolución en la época moderna causaba fascinación, tenía "una atracción magnética» que hacía de ella el eje rector de las sociedades, por ello se constituyó como «la religión pública» (1989: 9).

En la revolución se mezclan dos formas de experiencia de la temporalidad: la de la historia, y la del mito, según Paz, «Hija de la historia y de la razón, la Revolución es la hija del tiempo lineal, sucesivo e irrepetible; hija del mito, la Revolución es hija del tiempo cíclico» (1989: 9). Trepada sobre los hombros de la razón ilustrada, la revolución ha desplegado una marcha progresiva a través de la cual se han catalizado los procesos modernizadores, aquellos descritos por Marshall Berman (2010) como una «vorágine». El tiempo lineal instaurado por las revoluciones ilustradas o racionales establece un vínculo particular con el pasado. Por esto Jürgen Habermas precisaba lo siguiente: «el término [modernidad] aparece en todos aquellos periodos en que se formó la conciencia de una nueva época, modificando su relación con la antigüedad» (2004: 54). En la modernidad se politiza e ideologiza el tiempo; éste con todas sus connotaciones filosóficas, políticas e ideológicas en la modernidad se redujo a otra palabra: progreso.

La repetición contenida en el mito se convierte en algo negativo, representa el estancamiento y la ausencia de progreso, a su vez, significa la imposibilidad de alcanzar las promesas modernas de bienestar y abundancia. Por ello, Octavio Paz señalaba lo siguiente: «La naturaleza de la Revolución es dual pero nosotros no podemos pensarla sino separando sus dos elementos y desechando el mítico como un cuerpo extraño" (1989: 9). La revolución para Paz también es mito, en su seno germina el deseo de un regreso al origen: momento en el cual la desigualdad y la injusticia aún no se hacen presentes. Todo acontecimiento revolucionario ha partido de esa aspiración utópica; sin embargo, en algún punto el tiempo del mito es reemplazado por la temporalidad histórica. Paz señalaba:

[...] la Revolución comienza como promesa, se disipa en agitaciones frenéticas y se congela en dictaduras sangrientas que son la negación del impulso que la encendió al nacer. En todos los movimientos revolucionarios el tiempo sagrado 
del mito se trasforma inexorablemente en el tiempo profano de la historia (1989: 10).

Siguiendo a Paz, la historia nace en el momento en el que alguien dice «esto es mío» (1989: 9), es decir, con el surgimiento de la propiedad privada; en ese preciso momento nace la injusticia y la desigualdad. La historia es el relato secularizado de la revolución y es, a la vez, el tiempo del nacimiento de la opresión. Para el autor de El arco y la lira, las revoluciones del siglo $\mathrm{XX}$ habían sido subsumidas por la inercia del tiempo histórico; la ausencia del mito en su desarrollo, ineludiblemente, las llevó a abandonar las promesas y utopías con las que habían iniciado: las revoluciones se anunciaban como procesos emancipadores; sin embargo, concluyeron negando su primer impulso y generando nuevas formas de opresión y control.

Para Paz, el año de 1989 anunciaba «el fin de una era: presenciamos el crepúsculo de la idea de Revolución» (1989: 11). Con esto, el poeta mexicano parecía despedir a uno de los motores principales de la modernidad. Mientras Octavio Paz anuncia la muerte de la idea de revolución, Severo Sarduy no renunciaba a ella. Así como se muestra un vínculo filial en Paz en Oriente, también se trasluce un límite en su complicidad delineado por la persistencia de la revolución en la escritura de Sarduy.

La diferencia de los posicionamientos frente a la idea de revolución de Paz y Sarduy puede explicarse a través de la crítica realizada por Bolívar Echeverría a la postura paziana. El filósofo marxista consideraba que en las ideas de Paz se ausentaba la voluntad de diferenciar entre el mito revolucionario y la idea de revolución. También señalaba, con extrañamiento, que en una época marcada por «cambios radicales e insospechados» se mencionara la muerte del concepto de revolución. Resultaba paradójico hablar, como lo había hecho el nobel mexicano, del ocaso de la revolución en un momento en el que se hacían más notorios los cambios sociales en «el conjunto de la vida civilizada» (2018: 25), propiciados por la marcha de la revolución moderna capitalista.

Si Severo Sarduy no abandonó la idea de revolución fue quizá porque consideraba que la desilusión provocada por las revoluciones no necesariamente debía llevar a su negación, sino a su reelaboración conceptual. Echeverría se cuestionaba lo siguiente frente a la actitud de Octavio Paz:

¿Despejarse la cabeza de ilusiones revolucionarias absolutistas tiene que
significar para la izquierda un abandono de su orientación revolucionaria? ¿O
puede ser, por el contrario, una oportunidad de precisar y enriquecer su concepto
de revolución? (2018: 27).

Frente a este dilema de las izquierdas y contrariamente a la postura de Paz, Sarduy se decantó por reivindicar la revolución desde el neobarroco y, con este movimiento, la estética sarduyana se declaraba como netamente moderna. En este sentido, no podría hablarse de una estética posmoderna (tal como lo hacen: Kushigian, 1999; Castañón, 1999; Santí, 1980; Chiampi, 2001) porque la presencia del concepto de revolución la acota dentro de lo 
moderno. Al neobarroco no habría que criticarlo exclusivamente desde la forma, sino desde lo que motiva esa forma. En el neobarroco, el motivo y la forma se funden, revolución y estructura se determinan mutuamente, haciendo posible hablar de una técnica neobarroca ${ }^{6}$. El concepto de revolución, con la plasticidad que le ha caracterizado en la historia de la modernidad, adquiere otra dimensión en el neobarroco; en él, el lenguaje y el cuerpo tienen un carácter expresamente revolucionario; a través de ellos se plantea la posibilidad de derrumbar aquello que Sarduy denominó el «espacio mental burgués» y el «fundamento epistémico que lo sostiene».

\title{
2. La revolución después de la revolución
}

Rafael Rojas subraya en La vanguardia peregrina (2013) que Bolívar Echeverría toma el neobarroco sarduyano con la intención de explorar la posibilidad de existencia de otras modernidades. La lectura hallada en $L a$ modernidad del barroco (1998), así como en Modernidad y blanquitud (2010), sobre lo barroco tiene diversos puntos de encuentro con el neobarroco de Sarduy. Aunque las referencias al escritor cubano son pocas en estos textos del filósofo marxista, la idea anterior se puede sostener con una lectura entrecruzada, algo ya realizado de manera sintética, pero muy sugerente, por Gustavo Guerrero en «Severo Sarduy y Bolívar Echeverría: ética y estética del Barroco en la América Latina de fines del siglo $X X$ », donde el crítico venezolano señala: «el filósofo ecuatoriano construye su teoría como situándose por momentos en la continuidad de las ideas del escritor cubano, o incluso como si tratara de prolongar algunos de sus hallazgos» (2016: 101). Una lectura más amplia que entrelace la obra de los dos autores resulta necesaria. Por lo pronto, tomo algunos aspectos de la obra de Bolívar Echeverría para extender la comprensión de la idea de revolución en el neobarroco, tomando en consideración la idea de Gustavo Guerrero de que en algunos momentos la propuesta del filósofo naturalizado mexicano pareciera una extensión de ideas arrojadas anteriormente en la obra de Severo Sarduy.

\section{En «Modernidad y revolución», Bolívar Echeverría se pregunta:}

\begin{abstract}
¿En qué medida la idea de revolución que emplea Marx -la misma que de alguna manera ha dominado en la historia del socialismo y del comunismo durante todo el siglo $\mathrm{XX}$, y que ha permeado en general todo el discurso político contemporáneo- es una idea en la cual está en juego el problema, planteado por la Escuela de Frankfurt, de un rebasamiento insuficiente de la idea espontánea de revolución que es propia de la modernidad burguesa capitalista? ¿En qué medida, por lo tanto, la idea misma de revolución debe ser representada y replanteada en toda su radicalidad? (1998: 67).
\end{abstract}

La forma de plantear estas preguntas indica que la noción de revolución en Marx y, por consiguiente, la del pensamiento emanado de él, ha estado impregnada por la lógica burguesa, incluso cuando se esperaría una escisión radical respecto a ella; no obstante, para Bolívar esto no ha sido así. Al contrario de lo esperado, el socialismo y el comunismo han abrevado del concepto de revolución generado por la modernidad capitalista. Pero lo interesante aquí, es la urgencia de replantear la idea de revolución, algo que realizó Severo Sarduy al integrar elementos del marxismo con la crítica a la metafísica occidental y al logocentrismo. 
Las ideas que dieron sustento al neobarroco se fueron forjando en las publicaciones que realizó Sarduy en la revista Mundo Nuevo en los años sesenta. Estos escritos fueron reunidos y publicados en 1969 bajo el nombre Escrito sobre un cuerpo, libro que para el cubano tenía dos ejes motores, tal como se lo explicó en una entrevista a su amigo y director de Mundo Nuevo, Emir Rodríguez Monegal. El primero de ellos era la relación cuerpo-escritura; el segundo, no es tan evidente a pesar de ser nodal para una lectura del neobarroco como estética disidente producida por un escritor cubano exiliado en un contexto caracterizado por un deseo teórico de relectura de Marx. En el siguiente fragmento de la entrevista con Rodríguez Monegal, Sarduy explica ese segundo eje de este modo:

\begin{abstract}
Pero el libro tiene, o quisiera tener, otro módulo teórico. Sería el siguiente: el soporte de la burguesía no sería el carácter factual de un sistema económico, como hemos creído, practicando una lectura un poco directa, digamos, de Marx, sino un sistema de escritura. Uno de los sucedáneos de este sistema de escritura es precisamente la economía. Es decir, hay un tipo de escritura que sirve de sustrato epistémico a la burguesía, a todo sistema instaurado. La economía no es más que una de las cifras visibles de este código central. Minando la escritura, practicando la transgresión de sus leyes, desmoronamos todo el edificio del pensamiento común. A la pregunta frecuente: ¿Para qué sirve la literatura?, podríamos responder: ¿Para qué sirve todo lo que no es literatura, incluida la narrativa tradicional? Todo lo que no es literatura no hace más que trabajar, reiterándola en su funcionamiento, al nivel de las escrituras manifiestas, no al nivel de la verdadera escritura central que consolida al régimen y sustenta sus redes subyacentes. Por supuesto, no hablo de la burguesía de un lado o del otro, sería simplificar mucho las cosas. Hablo del espacio mental burgués (Sarduy, 1970).
\end{abstract}

Lo primero que salta a la vista de lo anterior es la referencia a Marx, esto es algo que poco se lee en la obra ensayística de Sarduy; sin embargo, es remarcable pues nos habla de las coordenadas de pensamiento con las cuales armó el andamiaje de su neobarroco revolucionario. Cuando Sarduy escribe: «barroco que recusa toda instauración, que metaforiza el orden discutido, al dios juzgado, a la ley transgredida» (1999b: 1253), ese dios y esa ley es el espacio semiótico que sirve como «fundamento epistemológico» a la vida burguesa, ese fundamento es «la entidad logocéntrica» mencionada anteriormente. Las palabras de Sarduy en la cita anterior contienen una lectura muy particular de Marx para ese momento: el filósofo alemán es leído a través de la deconstrucción de Jacques Derrida, quien para ese momento aún no había escrito Espectros de Marx ${ }^{7}$. Sarduy describe a la economía como producto de un sistema de escritura ubicado a manera de centro u origen rector de lo social; esto quiere decir que el aspecto material de lo económico se sustenta en una producción simbólica anterior: el «fundamento epistemológico» al cual se refiere. La relación entre escritura y episteme que realiza el escritor cubano remite a lo que Derrida planteó al respecto en De la gramatología: «la escritura es la condición de la episteme» (2010: 37). Puesto así, es más factible comprender por qué Sarduy apunta a que hay una escritura que «sirve de sustrato epistémico a la burguesía». Desde la perspectiva revolucionaria de Sarduy, esa escritura debe ser minada, y el modo de hacerlo es contraponiendo otro tipo de escritura: la neobarroca. 
La postura anterior no implicó un simple movimiento en donde ahora la estructura quedaba determinada por la superestructura, ya que ambas son tomadas como producto de esa «escritura central». Al situar el soporte de la burguesía en una escritura y no inmediatamente en lo económico, Sarduy buscó ligar la crítica a la economía política con la crítica a la metafísica occidental, desarrollada como una crítica al logocentrismo por Derrida. La crítica a la economía política emprendida por Marx, sin ser desplazada, le abre lugar a la crítica al logocentrismo, y esto es así porque para Sarduy la economía política se estructura previamente desde una metafísica. Vista de este modo, la economía burguesa a la cual el neobarroco se encarga de amenazar es otra de las manifestaciones del logocentrismo que bien podría nombrarse en este caso como un capitalogocentrismo.

En El discurso crítico de Marx (1986), escrito antes de sus análisis sobre el barroco, Bolívar Echeverría sugiere algo similar: la importancia del trabajo de los signos en un proyecto que tiene en mente la idea de revolución. Para él existía, igualmente, una relación entre la «praxis social» y el campo semiótico. Para que una teoría pueda ser realmente revolucionaria debe remover los fundamentos codificados en el lenguaje sobre los que se han construido las teorías anteriores:

La «verdad» de la producción teórica sólo puede consistir en su «poder» revolucionario específico, es decir, en la realización concreta, en su plano conceptual, de esa restructuración o transformación radical del campo semiótico que es esbozada por el proceso revolucionario y que debe desarrollarse como componente esencial del mismo. [...] Así, de lo que se trata para la teoría, si pretende ser «verdadera», es de ser revolucionaria: de intervenir en el sentido del proceso que decide las posibilidades de su trabajo específico (2017: 56).

Una filosofía revolucionaria reestructura el campo semiótico que le precede. Todo acto revolucionario, desde lo teórico, tiene como tarea imprescindible el trabajo con los signos y la compresión del espacio simbólico del contexto en el que se sitúa. Así como hay literatura que repite los valores de la modernidad burguesa, también hay una filosofía que hace lo propio. Lo rescatable de esta última parte de Echeverría es la idea que comparte con Sarduy sobre el trabajo con los signos; éste es esencial dentro de una voluntad revolucionaria. Para Sarduy, la literatura tradicional, entendida como aquella que trabaja con los valores burgueses, especialmente los del realismo, al igual que todo lo que no es literatura mantiene el funcionamiento del «espacio mental burgués».

La relación que tuvo el escritor cubano con el grupo Tel Quel incidió en la estructuración de varias de las ideas motores del neobarroco, en gran medida esa relación permitió el contacto del escritor cubano con la obra de Jacques Derrida, Michel Foucault, Gilles Deleuze, Julia Kristeva, Roland Barthes, entre otros. Sarduy llegó a afirmar que debía a ese vínculo su acercamiento al marxismo, el psicoanálisis y la lingüística, teorías sin las cuales nadie «puede llegar a una crítica seria» (1999b: 1825). A pesar de esto, su relación con el ámbito teórico francés del momento también se traducía en una apreciación crítica de los movimientos ideológicos del grupo Tel Quel del cual se consideraba tan solo un acompañante. Como Sarduy lo decía: «hice muy bien en no seguir sus virajes políticos e intelectuales, que llegaron a una burda expresión de la moda y que ha 
llevado a muchos de ellos a la práctica de una literatura del chisme, la anécdota fácil, cuando no a la calumnia o a la denuncia» (1999b: 1825). Por lo anterior, no se puede considerar el desarrollo de la estética neobarroca a la par de los cambios teóricos y políticos del grupo Tel Quel. Aunque se aprecie en su interior una asimilación de algunos conceptos posestructuralistas, estos no funcionan como herramienta conceptual de fácil y directa aplicación porque son recontextualizados bajo las pautas del barroco latinoamericano; por tanto, intentar verificar si en el neobarroco están bien comprendidos y aplicados los conceptos de Jacques Derrida, Roland Barthes, Jacques Lacan, Michel Foucault, Julia Kristeva e, incluso, Mijaíl Bajtín, como lo hace Pierrette Malcuzynski (1994) sobre los últimos dos, redunda en una labor puntillosa y sutil, pero inútil.

Para Rafael Rojas, un amigo cercano de Severo Sarduy y a quien consideró su maestro, Roland Barthes:

como muchos de sus contemporáneos, pensaba entonces que la economía política de los símbolos, correspondiente a la nueva fase capitalista, demandaba una revolución del concepto revolución, entendido a la clásica manera leninista, maoísta o fidelista. Los nuevos sujetos revolucionarios no soportaban, ya, la vieja fórmula de definición totalizante u homogeneizadora del «proletariado» $\mathrm{o}$ el «pueblo» y exigían una pluralización civil y moral, donde cupiera esa tribu de enanos, boleristas y drag queens que retrataba Fellini y Sarduy (2013: 85).

El historiador cubano escribe esto en relación al texto La cara barroca de Barthes, donde el semiólogo francés etiquetó a la novela De donde son los cantantes como revolucionaria (1994a: 283). Esta novela de Sarduy es un espacio escritural donde el significante se vuelve «oblicuo» y, por consiguiente, pierde toda referencialidad. Todo se resume y reduce al lenguaje, «no hay nada detrás del lenguaje», decía Roland Barthes. Para los posestructuralistas y para Sarduy era necesario liberar al significante de la «hegemonía de fondo, del significado o del campo semántico previamente ideologizado» (Rojas, 2013: 84). En este sentido la palabra revolución debía pasar por el mismo proceso, era necesario liberarla de las anteriores presuposiciones ideológicas que la constreñían. La estética sarduyana rescata a la revolución de los resultados de la propia revolución establecida como el orden hegemónico. En el ámbito del lenguaje, como explicaba Barthes, la revolución inicia con una voluntad acrática, en contra de la doxa: el orden del código; sin embargo, cuando la revolución se encamina del margen hacia el centro excluye de sí el deseo impugnador y su lenguaje se torna encrático (1994b: 129), en otras palabras, se convierte en la lengua de un Estado regulador y en el modelo ideológico del lenguaje. En este sentido, el neobarroco es un lenguaje acrático y busca mantenerse así.

\subsection{La revolución neobarroca del lenguaje y el cuerpo}

La revolución burguesa posee tintes metafísicos: propone una nueva esencia de lo humano vinculada con una reorganización del mundo natural. La revolución es producida, y a la vez produce, un tipo de sujeto particular. El sujeto de la revolución burguesa es capaz de crear lo nuevo de la nada, puede disolver las formas de vida tradicionales y reorganizar lo social, lo 
político y lo económico desde la lógica de la acumulación de capital. Esta manera de producir ejemplifica la forma «clásica» de trabajo (Sarduy: 1402), y funda una temporalidad homogénea y totalmente abierta al futuro. El individuo enajenado en la producción sólo puede existir en un mundo

donde rige la economía mercantil de corte capitalista, es decir, centrada en torno a un sujeto absolutamente creador —el valor que crea ex nihilo más valor, el capital o dinero que se autoincrementa milagrosamente- [...]. Ser creador consiste en poner valor (Echeverría, 1998: 69).

Este sujeto productor de valor tiene existencia en un tiempo que oblitera imperiosamente la tradición y el pasado; si llega a recurrir a él es en forma de folclor: ejemplificación de un pasado ya superado. En la modernidad capitalista la economía sustentada en el valor de uso es reemplazada por una donde prevalece la valorización del valor; este cambio exige un individuo con una subjetividad diferente.

Para Severo Sarduy, las sociedades capitalistas dieron a luz al homo faber «el ser-para-el-trabajo» (1999b: 1402); éste constituye la garantía del trabajo útil para la producción de plusvalía y acumulación de capital. La fuerza corporal de este sujeto ha tenido como finalidad la creación de valor. Dentro de un proyecto de modernidad alternativa, los dispositivos de control y disciplinamiento necesarios para la formación de este individuo son indefectiblemente impugnados, es decir, se aspira a reconfigurar la metafísica del sujeto de la modernidad capitalista. En la obra de Sarduy existe la voluntad de imaginar otro sujeto fuera de esta lógica, por tal motivo encontramos en sus novelas personajes que no responden a la metafísica del mundo moderno burgués. El máximo ejemplo de esto sería la figura del travesti, plasmada en una novela como Cobra y ampliamente comentada en su ensayo titulado La simulación.

La operación erótica de travestirse, de devenir continuamente otro, desarma las lógicas del poder económico el cual determina las posibilidades corpóreas del sujeto, delimitándolas al uso exclusivo de producción de capital. En este sentido, Cobra o el travesti es la imagen opuesta del homo faber. La trasformación corporal, unida a la erotización de los cuerpos, se convierten en acciones de resistencia. Para Severo Sarduy:

Nuestro cuerpo es una máquina erótica que produce deseo «inútil», placer sin objetivo, energía sin función. Máquina de placer en constate gasto y en constante reconstitución. Máquina barroca revolucionaria que impide a la sociedad represiva su propósito (apenas) oculto: capitalizar bienes y cuerpo (Sarduy, 1976: 19).

El trabajo con el cuerpo y su conceptualización como máquina neobarroca revolucionaria en la obra de Sarduy, tienen una relación importante con un aspecto que Michel Foucault tenía en consideración: en un contexto de un proceso político, el «cuerpo es una de las piezas más importantes, sino esenciales» (1978: 105). El autor de Vigilar y castigar señalaba esto al momento de sostener también que en una sociedad capitalista «la dominación del cuerpo debía ser pesada, maciza, constante, meticulosa» (106). Pensar el poder en relación al cuerpo y no a las formas ideológicas era una manera de análisis incluso más materialista que el propuesto 
tradicionalmente por el marxismo. Para Foucault, el marxismo había ocultado el análisis sobre el cuerpo, que sí estaba en Marx, en provecho de una reflexión sobre la conciencia y la ideología.

Sarduy encuentra en el cuerpo humano el resquicio para replantear el concepto de revolución y el espacio propicio para llevarla a cabo. Los cuerpos son barrocos porque tienden a producir y derrochar energía inútilmente. En esta característica corpórea ligada al erotismo y la sexualidad está el llamado a la desobediencia al sistema que regula y direcciona la energía a formas productivas. Pero el cuerpo barroco no sólo es retratado mediante la representación erótica de los personajes en las novelas de Sarduy. También en Cobra la escritura sobre el cuerpo, el tatuaje, vuelve a los cuerpos barrocos. Los cuerpos tatuados son cuerpos camuflados y el camuflaje, elemento relacionado al travestismo, es una forma de mimetismo ofensivo, es decir, en una acción de resistencia. La desnudez del cuerpo va desapareciendo y en su lugar aparecen los pliegues barrocos; el cuerpo se convierte en espacio de representación y simulación donde elementos disímiles como el jeroglífico, el arabesco, el arcoíris y el guion teatral se encuentran.

El neobarroco desde el espacio del lenguaje y los signos reelabora la imagen del sujeto formado por la economía moderna capitalista, «dessituándolo»: lo arrastra de un mundo clásico organizado a partir de una perspectiva única y centrada, donde el tiempo reinante es homogéneo y lineal, a uno barroco dominado por el deseo de «repetición y ruptura» (Sarduy, 1999b: 1228) de lo clásico. La repetición es consecuencia de una pulsión que se lanza en una búsqueda infructuosa del objeto perdido; sin embargo,

[la] constatación del fracaso no implica la modificación del proyecto, sino al contrario, la repetición del suplemento; esa repetición obstinada de una cosa inútil [...] es lo que determina al barroco en tanto que juego en oposición a la determinación de la obra clásica en tanto que trabajo (1999b: 1251).

La repetición se convierte en juego y representación teatral: simulación que irrumpe en el flujo temporal de la realidad clásica sin ningún fin útil o de producción de valor. Por otro lado, la ruptura se origina a raíz de la desrealización de la forma clásica de producción y del sujeto que ésta necesita. El juego permite la apertura de una dimensión donde la seriedad de la vida productiva se pone en entredicho por medio de la parodia y el carnaval característicos del neobarroco. Las reglas quedan suspendidas para establecer otras. No obstante, para ello es preciso una reflexión anterior del sistema: la «escritura central» que se cancela en la simulación. Para Bolívar Echeverría, el juego «trae la experiencia de una pérdida fugaz de todo soporte» (2013: 190); a decir del escritor cubano, el «fundamento epistémico» de una realidad histórica se suspende en el juego, en la simulación y en la teatralidad.

El tiempo del neobarroco es el tiempo de la repetición o iteración por eso su escritura es repetitiva. Decía Severo Sarduy: «La repetición (también en el sentido que en francés tiene esta palabra: ensayo de una obra) es el soporte último de la imaginación sádica y, sin duda, el de toda perversión» (1999b: 1124). La perversión, para el escritor cubano, trasciende la forma 
natural de la vida. La metáfora barroca, por ejemplo, es la trasgresión de la expresión natural denotativa del lenguaje, por ello señalaba en una entrevista: «Con la retórica barroca, el erotismo se presenta en tanto que ruptura total del nivel denotativo, directo y natural del lenguaje» (Sarduy, 1976: 18), esa función denotativa soporta «al buen sentido, moralista y natural en que se basa toda la ideología del consumo y la acumulación» (16). Esas formas son el resultado social de la vida moderna capitalista, dada como natural, ésta precisa de un lenguaje asertivo estructurado para satisfacer una economía del tiempo útil para el trabajo. Los elementos considerados por Severo Sarduy como barrocos: sustitución, proliferación, condensación, elisión, y digresión funcionan en sus novelas, por ejemplo, como modos de hacer fluir el tiempo narrativo de manera no lineal; incluso hay momentos en los cuales las digresiones son tan amplias que es fácil perder el hilo de los sucesos.

La estética neobarroca, desde su escritura repetitiva, también busca la fijeza: la detención del movimiento; sin embargo, esto no pude ser tomado de forma negativa, pues no se trata de un «quietismo indiferente o de un abandono del mundo», es decir, no es una evasión de la realidad, sino una «desviación esteticista de la energía productiva» (Echeverría, 2013: 186) donde los sujetos ya no son máquinas productoras de valor.

Cuando Severo Sarduy escribe «Barroco de la revolución» evoca un tiempo diferente al de la modernidad capitalista, centrado en «barrer todas las formas tradicionales para sustituirlas totalmente por otras nuevas» (Echeverría, 2013: 74). El neobarroco se estructura con la voluntad de ruptura, repetición y discontinuidad. Estos tres elementos se revuelven en el juego neobarroco a razón de hacer nacer un tiempo subversivo. Bolívar Echeverría, con un talante similar hablaba de dos tiempos en la experiencia humana: el «tiempo de la discontinuidad absoluta» y el de «la continuidad absoluta»; en el primero se revelan «momentos extraordinarios de la existencia histórica» en los cuales la vida cotidiana de la producción del trabajo se suspende y entra en cuestionamiento; en este tiempo se reestructura y asedia la identidad que la vida cotidiana impone al sujeto $u$ homo faber; en el segundo, la existencia humana está condicionada por el tiempo del crear donde se reafirman los modos de vida existentes. El autor de La modernidad de lo barroco caracteriza el primer tiempo de manera similar a como lo hace la propuesta neobarroca, en cierta medida se puede apreciar en esa descripción la continuidad con las ideas del escritor cubano:

En el momento extraordinario, el código general de lo humano junto con la
subcodificación específica de una identidad cultural concreta en una situación
determinada - que son los que dan sentido y permiten el funcionamiento de una
sociedad- entran a ser re-formulados o reconfigurados en la práctica, son
tratados de una manera que pone énfasis en la función meta-semiótica (y
metalingüística) de la vida como proceso comunicativo. En el tiempo de la rutina,
en cambio, el uso que se hace de ellos es completamente respetuoso de su
autoridad, concentrado en cualquier otra de las funciones comunicativas, menos
la autorreflexiva (2013: 187).

Esta cita de Bolívar resulta bastante rica en un análisis contrastivo con la obra ensayística de Severo Sarduy. En primera instancia el momento extraordinario permite observar la estructura del lenguaje sobre la cual se sostiene la vida cotidiana del trabajo. Aquí toma gran sentido lo que el autor 
de Cobra refiere cuando dice que el neobarroco con su «lenguaje pinturero, a veces estridente, abigarrado y caótico» busca subvertir el «logocentrismo» condicionante y estructurador de la forma clásica de vida. El neobarroco se centra en su soporte lingüístico y, a razón de ello, pone atención al aspecto meta-semiótico y autorreflexivo del lenguaje, mermando la función comunicativa persistente en la vida rutinaria.

Para Severo Sarduy una manera de trasgresión se verificaba en el «pensamiento que se piensa a sí mismo» (1999b: 1128). La actividad de pensar por sí misma no es trasgresora, hay pensamiento que ayuda a reafirmar la vida burguesa capitalista. Sarduy señalaba:

(No hablo de la trasgresión pueril que es el "arte de denuncia»: el pensamiento burgués no sólo no se molesta, sino que se satisface ante la representación de la burguesía como explotación, del capitalismo como podredumbre). Lo único que la burguesía no soporta, lo que la saca de quicio es la idea de que el pensamiento pueda pensar sobre el pensamiento, de que el lenguaje pueda hablar del lenguaje, de que un autor no escriba sobre algo, sino que escriba algo (1129).

Evidentemente Sarduy buscaba posicionarse en un espacio aún más radical respecto a sus colegas escritores latinoamericanos, a varios de ellos los habría encasillado en ese acto pueril del «arte de denuncia». El realismo aun en su versión revolucionaria sirve de soporte a la identidad de la vida burguesa; ésta se reafirma en él. Este tipo de literatura se hace del código del lenguaje que sostiene la vida como "continuo absoluto», por esta razón se mantiene en un nivel donde la vida humana no queda enteramente cuestionada. Espacio, tiempo, sujeto y lenguaje son conservados.

La apuesta de Sarduy es por la producción de un arte no de denuncia, sino «del destronamiento y la discusión» que quiebre la homogeneidad del «fundamento epistémico» (1999b: 1252) de la vida rutinaria por medio de una praxis: la escritura neobarroca, desligada, por su puesto, de las técnicas establecidas y precodificadas por la modernidad burguesa. Por ello, el escritor cubano se pregunta: «¿Qué significa hoy en día una práctica del barroco?» (1250). Con esta pregunta la escritura neobarroca es caracterizada como una "práctica», expuesta además como revolucionaria. Sarduy puede decir: «Barroco de la revolución» porque la estética neobarroca se asienta en el campo del quehacer social como técnica deconstructiva de los regímenes hegemónicos. Como señalaba Julia Kristeva: «El ejercicio del lenguaje como práctica supone un cambio en la concepción de la política» (1976: 80), por tanto, la lucha social es llevada al espacio de los signos y el concepto de revolución es reconfigurado desde ahí.

El neobarroco, en su aspecto reflexivo, teoriza sobre el campo de la vida social; cuestiona el tiempo, el trabajo, el lenguaje y al sujeto. Al tiempo que realiza esto, subraya el lazo existente entre la actividad humana y el ámbito semiótico. Para Sarduy, cierta literatura se relaciona con el mundo a guisa de reflejo pasivo, de una forma redundante en la cual no caben otras posibilidades, sino las establecidas; en ella el juego no tiene cabida. En este entendido, la poética sarduyana intenta reestructurar el campo de los significantes en un movimiento de negación de lo anterior. 


\section{Conclusiones}

Leer el neobarroco de Severo Sarduy considerándolo como una propuesta estética que se asigna a sí misma como revolucionaria abre una vía de comprensión de la obra del escritor cubano que muchas veces se oblitera en pos de resalar otros elementos que la constituyen. Su concepto particular y complejo de revolución surgió en un contexto especial de discusión política, ideológica y estética que involucró a una diversidad de intelectuales interesados en la reflexión acerca de las posibilidades de la revolución en un momento en el que las expectativas hacia las revoluciones gestadas desde las izquierdas se veían disminuidas. Leer el neobarroco obliterando su aspecto revolucionario derivaría en una interpretación desideologizante que únicamente dejaría al análisis su estructura compleja de escritura. Esto es lo que ha pasado con una parte importante de la crítica a la obra de Sarduy. El concepto de revolución que atraviesa toda esa escritura es el motivante de esta estética que se sumó a los debates teóricos de su época y con especial énfasis a los latinoamericanos, algo que comúnmente no se comenta, pues incluso se ha llegado a considerar a la obra de Sarduy como más cercana a las preocupaciones teóricas y estéticas francesas de su época. Aunque no se puede pasar por alto que Sarduy fue un lector muy cercano de las obras de los filósofos posestructuralistas, tampoco se puede olvidar que su acercamiento a estas se debió a una preocupación que tuvo como fin reflexivo lo latinoamericano y, especialmente, lo cubano. En el neobarroco confluyó la tradición barroca latinoamericana y el posestructuralismo francés, en esta convergencia la voluntad revolucionaria siempre estuvo presente.

El problema general de la crítica al neobarroco, cuando toma en consideración su aspecto revolucionario, es que recoge el término revolución y lo coloca exclusivamente en la esfera de lo estético para hablar de una escritura revolucionaria, lo cual deriva inmediatamente en la etiqueta de escritura experimental; también sucede que se toma la revolución como una mera referencia y no como una elaboración conceptual desde la estética que se fue construyendo en el trascurso de sus ensayos y su novelística. En este sentido este trabajó ha tenido la finalidad de dar cuenta de esa elaboración conceptual de la revolución dentro del neobarroco en el que se liga una crítica anticapitalista con la crítica a la metafísica occidental y al logocentrismo. Este replanteamiento de la revolución a través de estos elementos es un elemento central del neobarroco.

\section{Bibliografía citada}

ASENSI, M. (2006): Los años salvajes de la teoría, Valencia: Tirant lo blanch.

BARTHES, R. (1994a): «La cara barroca» en El susurro del lenguaje. Más allá de la palabra y de la escritura, Barcelona: Paidós, 281-284.

BARTHES, R. (1994b): «La división de los lenguajes» en El susurro del lenguaje. Más allá de la palabra y de la escritura, Barcelona: Paidós, 119-134.

BENJAMIN, W. (2018): «El autor como productor» en Iluminaciones, Barcelona: Taurus, 101-118.

BERMAN, M. (2010): Todo lo sólido se desvanece en el aire, México, D.F.: Siglo $\mathrm{XXI}$. 
CASTAÑÓN, A. (1999): «Severo Sarduy: del barroco, el ensayo y la iniciación», en Obra Completa, Tomo II, Gustavo Guerrero y François Wahl (eds.), Madrid: ALLCA XX, 1644-1648.

CHIAMPI, I. (2001): Barroco y modernidad, México: FCE.

DERRIDA, J. (2010): De la gramatología, México, D.F.: Siglo XXI.

DERRIDA, J. (2012): Espectros de Marx, Madrid: Trotta.

ECHEVERRÍA, B. (1998): «Modernidad y revolución» en Valor de uso y utopía, México, D.F.: Siglo XXI, 61- 76.

ECHEVERRÍA, B. (2017): El discurso crítico de Marx, México: FCE.

ECHEVERRÍA, B. (2013): La modernidad de lo barroco, México: Era.

ECHEVERRÍA, B. (2018): Las ilusiones de la modernidad, Ciudad de México:

Ediciones Era.

FOUCAULT, M. (1978): «Poder-cuerpo», en Microfísica del poder, Madrid: Las Ediciones de la Piqueta, 103-110.

GONZÁLEZ ECHEVARRÍA, R. (2002): «Plumas, sí: De donde son los cantantes y Cuba» en Crítica práctica/ práctica crítica, México, D.F.: FCE, 214-243.

GUERRERO, G. (2016): «Severo Sarduy y Bolívar Echeverría: ética y estética del Barroco", en Ugalde, S. (ed.), Políticas y estrategias de la crítica: ideología, historia y actores de los estudios literarios, México, D.F.: Siglo XXI, 101-118.

HABERMAS, J. (2004): «Modernnidad: un proyecto incompleto» en Casullo, N. (ed.), El debate modernidad-posmodernidad, Buenos Aires: Retórica, 53-64.

KOSELLECK, R. (1994): «Criterios históricos del concepto moderno de revolución», en Futuro pasado. Para una semántica de los tiempos históricos, Barcelona: Ediciones Paidós, 67-86.

KUSHIGIAN, J. (1999): «Severo Sarduy, orientalista posmodernista. En camino hacia la autorrealización. Un ménage a trois: Cobra, Colibrí y Cocuyo» en Sarduy, S. Obra Completa, Tomo II, Gustavo Guerrero y François Wahl (eds.), Madrid: ALLCA XX, 1605-1619.

KRISTEVA, J. (1976): «Sujeto en el lenguaje y práctica política» en Verdiglione, A. (ed.), Locura y sociedad segregativa, Barcelona: Anagrama, 75-94.

MALCUZYNSKI, P. (1994): «El campo conceptual del (neo)barroco (Recorrido histórico y etimológico)», Criterios, 32, 131-170.

Marx, K. (1974). La ideología alemana. Crítica de la novísima filosofía alemana en las personas de sus representantes Feuerbach, B. Bauer y Stirner y del socialismo alemán en las de sus diferentes profetas, Barcelona: Ediciones Grijalbo.

PAZ, O. (1989): «Poesía, mito, revolución», Vuelta, 152, 8-12.

ROJAS, R. (2018): La polis literaria. El boom, la Revolución y otras polémicas de la Guerra Fría, México: Taurus.

ROJAS, R. (2013): La vanguardia peregrina, México, D.F.: FCE.

ROMERO, C. (2007): Severo Sarduy en Cuba 1953-1961, Santiago de Cuba: Editorial Oriente.

SANTÍ, E. M. (1980): «Textual politics: Severo Sarduy», Latin American Literary Review, 16,152-160.

SARDUY, S. (2002): Antología, México, D.F.: FCE.

SARDUY, S. (1970): "Conversación con Severo Sarduy», entrevista de Emir Rodríguez Monegal, Revista de Occidente, 93, diciembre 1970, 315-343, [04/11/2021]

$<$ http://www.autoresdeluruguay.uy/biblioteca/emir rodriguez monegal/entrevista s/entrev 11.htm>

SARDUY, S. (1999a): Obra Completa, Tomo I, Gustavo Guerrero y François Wahl (eds.), Madrid: ALLCA XX.

SARDUY, S. (1999b): Obra Completa, Tomo II, Gustavo Guerrero y François Wahl (eds.), Madrid: ALLCA XX.

SARDUY, S. (1976): «Severo Sarduy: máquina barroca revolucionaria», entrevista, Fossey, J. M., entrevistador, en Aguilar Mora, J. (ed.), Severo Sarduy, Madrid: Ediciones Fundamentos, 15-25. 
TRAVERSO, E. (2018): «Melancolía de izquierda. Marxismo, historia y memoria», Ciudad de México: FCE.

${ }^{1}$ El presente artículo es resultado de una investigación más amplia titulada «Neobarroco y deconstrucción. Otra vía para pensar la identidad latinoamericana», auspiciada por el «Fondo para el Desarrollo del Conocimiento» (FONDEC-UAQ 2019/2021) de la Universidad Autónoma de Querétaro, México.

2 Manuel Asensi en Los años salvajes de la teoría recuerda cómo en su momento el grupo telquelista abogaba por una revolución tanto social como estética (2006: 91). En 1968, durante los acontecimientos del mayo francés, mostraron a través de su revista Tel Quel la necesidad de pensar la revolución también en el orden simbólico y del lenguaje. Como señala Manuel Asensi sobre el grupo telquelista: «Parecía urgente replantearse la revolución después de la revolución» (2006: 50).

${ }^{3}$ El libro Severo Sarduy en Cuba 1953-1961 de Cira Romero nos deja un panorama amplísimo del trabajo de Severo Sarduy en sus primeros años de formación. En él hallamos sus primeros poemas, cuentos, así como crítica literaria y de arte, textos publicados en diversas revistas, diarios y suplementos culturales. En varios de estos textos de crítica de arte, Sarduy se muestra entusiasta con la Revolución e incluso considera la labor del escritor puede ser útil para los fines revolucionarios: «los escritores pueden ser sumamente útiles a la sociedad. Útiles precisamente en un proceso como éste que lleva la actual Revolución» (2007: 139).

${ }^{4}$ En su libro Melancolía de izquierda. Marxismo, historia y memoria (2018) Enzo Traverso describe este contexto del siguiente modo: "Junto a la oficial y ya desacreditada historia monumental del comunismo, había un relato histórico diferente, creado por la Revolución de Octubre, en la cual se habían inscripto muchos otros acontecimientos epocales, desde la Guerra Civil española hasta la Revolución Cubana y Mayo del 68. [...] Tras la conmoción de noviembre de 1989, sin embargo, ese relato se desvaneció, enterrado bajo los restos del Muro de Berlín. La dialéctica del siglo XX estaba rota. En vez de liberar nuevas energías revolucionarias, el derrumbe del socialismo de Estado parecía haber agotado la trayectoria histórica del propio socialismo. La historia entera del comunismo quedaba reducida a su dimensión totalitaria» (2018: 25). Como señalaré poco más adelante esta interpretación de la historia fue interiorizada por varios intelectuales entre los cuales habría que añadir a Octavio Paz, pues el poeta mexicano terminó por reducir a los movimientos revolucionarios a totalitarismos.

${ }^{5}$ Koselleck en Criterios históricos del concepto moderno de revolución (1993) señala que el concepto de revolución en la modernidad se caracteriza por su plasticidad y en el trascurso de su escrito va señalando las diferentes connotaciones que ha adquirido ésta. ${ }^{6}$ Como dice Walter Benjamin en El autor como productor: "Con el concepto de técnica he nombrado aquel concepto que hace que los productos literarios resulten accesibles a un análisis social inmediato y, por tanto, materialista. Al mismo tiempo, dicho concepto de técnica depara el punto de arranque dialéctico desde el que es posible superar la estéril contraposición entre forma y contenido» (2018: 103)

7 Es conocido que el abordaje de Marx por parte de Derrida no fue de manera pronta en su obra. Espectros de Marx no fue publicado hasta 1993, justo el año de fallecimiento de Severo Sarduy, aunque esto no significa que Marx no hubiera estado presente en sus obras anteriores, en ellas encontramos en repetidas ocasiones referencias a él; sin embargo, el trabajo más amplio y específicamente dedicado a Marx se encuentra en este libro del noventa y tres. Cuando señalo que Sarduy hace una lectura de Marx tomando la deconstrucción de Jacques Derrida es en el sentido de que el cubano consideraba que el orden impuesto por el capital está íntimamente ligado a los signos, mismos que dan forma al pensamiento burgués. Esto hace recordar La ideología alemana (2019) de Karl Marx, texto al que recurre en repetidas ocasiones Jacques Derrida en Espectros de Marx para decir en una de esas veces: «así por ejemplo se puede hablar de un discurso dominante o de representaciones dominantes, y referirse, así, a un campo conflictual jerarquizado sin suscribir necesariamente el concepto de clase social con el que Marx determinó tan a menudo, sobre todo en La ideología alemana, las fuerzas que se disputan la hegemonía» (69). Es de subrayar que aquí Derrida y, anteriormente Sarduy en su interpretación de Marx y el funcionamiento de la sociedad burguesa, se contraponen a la corriente althuseriana que en gran medida despreciaba esta parte de la obra temprana de Marx. 